\title{
Exigências Ambientais Europeias: Novos Desafios Competitivos para o Complexo Eletrônico Brasileiro*
}

\section{Stela Luiza de Mattos Ansanelli}

Departamento de Economia, Faculdade de Ciências e Letras de Araraquara, Universidade Estadual Paulista

\section{RESUMO}

O objetivo deste artigo é avaliar as implicações das exigências ambientais europeias para equipamentos eletroeletrônicos sobre o complexo eletrônico brasileiro. Essas determinações, que tratam da eliminação de substâncias perigosas e da gestão dos resíduos de produtos eletrônicos, têm atingido não só as empresas do setor em nível internacional, mas também o complexo eletrônico brasileiro. A maior parte das empresas do setor no Brasil está se adequando ao requisito que restringe o uso de substâncias perigosas. Os principais efeitos desse processo são o desenvolvimento de inovações tecnológicas e alterações nas relações contratuais entre as empresas do setor. As filiais estrangeiras estão mais avançadas do que as nacionais quanto ao período de ajuste às novas regras e ao desempenho tecnológico alcançado, sinalizando um alinhamento com as estratégias das matrizes. $\mathrm{O}$ descumprimento dessas exigências pelas empresas nacionais evita ganhos comerciais e gera indagaçôes quanto às políticas que devem ser adotadas pelo país.

PalaVRas-CHAVE | Setor Eletrônico; Normas Ambientais Europeias.

Códigos JEL | Q56; O31; K32

* Gostaria de registrar meus agradecimentos às contribuições fornecidas pelos pareceristas. 


\title{
European environmental requirements: new competitive challenges for brazilian electronical sector
}

\begin{abstract}
The objective of this paper is to evaluate the implications of the european environmental requirements for electronic equipment on brazilian electronic industry sector. These determinations deal with elimination of hazardous substances and management of electronic products waste and have reached not only the electronic sector companies in international level, but brazilian electronic sector as well. Most brazilian companies of the electronic sector are getting complied with the requirement that restricts the use of hazardous substances. The main consequences of this process are technological innovations and changes on contractual relationships among companies. Foreign companies branches are more advanced than local ones in terms of timing of compliance to the new requirements and technological performance, showing an alignment with headquarter strategies. Not being complied with these requirements avoid companies to achieve commercial benefits and open space for questions about policies Brazil must take.
\end{abstract}

KeYWORDS | Electronic Sector; European Environmental Requirements.

JEL-CODES | Q56; O31; K32

\section{Introdução}

O setor eletroeletrônico é de fundamental importância econômica, pois é altamente dinâmico e inovador e permeia várias atividades produtivas, surgindo na base de outros setores. Apesar de não ser considerado poluidor do ponto de vista do uso de recursos naturais e da emissão de poluentes durante o processo produtivo, nos últimos anos, o ramo eletroeletrônico tem sido alvo de preocupação ambiental por parte das autoridades públicas das regiōes mais desenvolvidas, cujas políticas propostas para coibir o problema podem ter efeitos comerciais. 
A geração de resíduos de equipamentos eletroeletrônicos, conhecidos por "lixo eletrônico" ou "lixo tecnológico", tem sido crescente, em parte, devido ao aumento de consumo dessa categoria de bens e à redução do tempo de vida útil desses produtos que, atualmente, varia entre 2 e 4 anos. A disposição final desses resíduos, consequentemente, vem se tornando um problema de saúde pública, uma vez que os equipamentos contêm substâncias nocivas à saúde humana, animal e ao meio ambiente, como mercúrio, cromo, cádmio e chumbo.

A União Europeia (UE), preocupada com a geração de resíduos contendo substâncias perigosas desde os anos 1970, foi pioneira na discussão e definição de políticas específicas voltadas à produção de eletroeletrônicos e ao tratamento dos seus detritos que, em 1998, somavam 6 milhões de toneladas. Em 2003, a Comunidade Europeia promulgou dois regulamentos rigorosos e complementares que visam responsabilizar o produtor pelo tratamento desse lixo tecnológico coleta, reciclagem, recuperação e reutilização - e proibir o uso de substâncias perigosas na produção dos equipamentos eletroeletrônicos (EUROPEAN COMISSION, 2007).

Como consequência dessas medidas, que vigoram desde 2006 no âmbito do Acordo sobre Barreiras Técnicas ao Comércio da Organização Mundial do Comércio (OMC), a experiência internacional mostra que as empresas de vários países, situadas ou não na UE, vêm alterando seu processo produtivo para atender, sobretudo, à restrição do uso de substâncias perigosas. Além disso, muitos países têm implementado medidas similares às europeias, como o Japão, a China e os Estados Unidos, em alguns de seus estados (VOSSENAAR; SANTUCCI; RAMUNGUL, 2006).

Essas exigências ambientais podem assumir - dependendo das relações comerciais que certos membros estabelecem com a Comunidade Europeia e das dificuldades de adequação das empresas exportadoras aos regulamentos para comercialização na região - o papel de barreiras não tarifárias ao comércio. A análise dos efeitos desses regulamentos europeus para produtos eletrônicos, portanto, pode ser inserida na discussão atual das barreiras técnicas ao comércio com propósitos ambientais.

O objetivo deste artigo é discutir as implicações das novas exigências ambientais europeias para o complexo eletrônico brasileiro, a partir do enfoque da economia da tecnologia e da organização industrial. Duas são as principais motivações do estudo: a escassez de pesquisas que extrapolam a mera quantificação dos custos das barreiras não tarifárias; e o fato de que, no Brasil, o complexo eletrônico é um setor estratégico para o desenvolvimento industrial do país em termos de inovação tecnológica, participação no PIB industrial e encadeamentos com outros setores. 
Também é considerado o de maior potencial competitivo nas cooperações entre União Europeia e Brasil para pequenas e médias empresas (EUROPEAID, 2006).

$\mathrm{O}$ artigo apresenta cinco seções, incluindo esta introdução. Na segunda, realiza-se uma contextualização teórica dos efeitos das exigências ambientais externas a partir da economia da tecnologia e da organização industrial e, em seguida, são expostas essas exigências para equipamentos eletroeletrônicos. A quarta seção aborda, com ênfase nas principais variáveis de impacto dessas medidas, os resultados da pesquisa de campo realizada nas empresas do complexo eletrônico brasileiro. Por fim, são feitas as principais reflexōes e consideraçōes finais.

\section{Impactos das exigências ambientais externas: reflexões teóricas}

A fundamentação teórica que relaciona as exigências ambientais externas - ou mesmo as barreiras técnicas ao comércio - à competitividade dos setores afetados é escassa. Existem, principalmente, estudos de caso dispersos e a quantificação dos custos dessas barreiras. Mas é possível, por meio da economia da tecnologia, explorar essas ligações.

A análise da inovação tecnológica ambiental parte da visão neoschumpeteriana, segundo a qual as firmas tomam decisões visando se apropriar dos lucros e interagem com um ambiente caracterizado por incerteza e não disponibilidade tecnológica. Nesse sentido, as empresas tendem a efetuar um processo de busca inovativa por meio de procedimentos de "rotinas", ou seja, de padrões de soluçōes repetitivas para problemas semelhantes, que definem o que e como fazer as coisas. As rotinas constituem, portanto, uma forma de armazenamento do conhecimento e apresentam um caráter tácito e específico (NELSON; WINTER, 1982; DOSI, 1982).

De acordo com esse referencial, as inovações ambientais compreendem novos ou modificados processos, técnicas, sistemas e produtos que evitam ou reduzem danos ambientais e podem ser classificadas como inovaçōes técnicas ou organizacionais, as quais se diferenciam do processo de inovação tradicional acima descrito em relação aos fatores que afetam a oferta e a demanda de tecnologias ambientais. A oferta dessas tecnologias depende não apenas do conhecimento existente, mas especialmente das influências que a política ambiental pode exercer sobre as condiçôes de apropriabilidade dos resultados da inovação e sobre as expectativas das empresas quanto à geração de vantagens competitivas futuras decorrentes da regulação ambiental rigorosa. A demanda por tecnologias ambientais é dificultada 
por causa dos custos, incerteza e riscos econômicos envolvidos (KEMP; SOETE, 1990; KEMP; ARUNDEL, 1998).

A restrição ambiental pode ser vista como uma fonte de oportunidades tecnológicas para a criação de assimetrias tecnológicas, que conferem vantagens competitivas. A incorporação da questão ambiental na dinâmica inovativa ocorre em duas etapas. Em um primeiro momento, o processo de inovação depende de medidas coercitivas (que embutem custos) e ocorre, eventualmente, de forma espontânea. Em um segundo momento, as duas formas de desenvolvimento de inovações (a partir de medidas coercitivas e espontâneas) encontram-se presentes e acentuam a exploração de oportunidades tecnológicas ambientais, tornando a política ambiental mais complexa (ROMEIRO; SALLES FILHO, 1999).

A regulação ambiental também pode contribuir na tomada de decisão da empresa, uma vez que reduz a incerteza sobre investimentos ambientais, ajuda na compreensão e incorporação da questão ambiental, cria pressão motivando o progresso e aponta potenciais ineficiências de recursos e possíveis melhoramentos tecnológicos às companhias. De modo adicional, podem ocorrer efeitos compensadores dos gastos com inovação, como melhoria da qualidade dos produtos e redução do uso de insumos de emissão de poluentes (PORTER; VAN DER LINDE, 1995).

Porém, o grau de novidade e os tipos de inovações tecnológicas realizadas pelas empresas dependem dos tipos de instrumentos das políticas ambientais em vigor, respeitando a estrutura da indústria, as características da empresa e sua natureza tecnológica. Desse modo, observou-se que inovações radicais realizadas pelas firmas reguladas tendem a resultar de formas mais severas de regulação (como proibição de produtos e responsabilidade produtiva), enquanto inovações incrementais e difusão tecnológica têm sido as reaçôes mais recorrentes às medidas flexíveis, tais como especificidades tecnológicas, padrões de performance, padrões de produtos, subsídios e taxas de poluição (ORGANISATION FOR ECONOMIC CO-OPERATION AND DEVELOPMENT, 1999).

Quanto aos meios de medir o desempenho de inovação ambiental - aspecto fundamental mas ainda em discussão na literatura -, são sugeridos indicadores únicos de inovação ambiental, mas ajustados e similares aos do Manual de Oslo. ${ }^{1}$ Incluem-se indicadores como tipos de tecnologias ambientais, motivações da ino-

1 Os surveys existentes de inovação ambiental baseiam-se no Manual de Oslo, que integra uma série de documentos e visa fornecer linhas metodológicas para construção de indicadores de inovação tecnológica na OECD. Esse inclui poucas questões de relevância para a inovação ambiental, focando principalmente a redução dos insumos e efeitos da regulação ambiental. Outros estudos focalizam os tipos de tecnologia utilizados, sobretudo end-of-pipe ou clean tecnologies (KEMP; ARUNDEL, 1998; ANDERSEN, 2005). 
vação ambiental, gastos com pesquisa e desenvolvimento (P\&D), fontes e custos da informação, apoio do governo, política da empresa e sistemas de gestão ambiental utilizados, relações de cooperação e local de inovação (KEMP; ARUNDEL, 1998).

De modo adicional, além de constituírem um dos principais indicadores, os gastos com $\mathrm{P} \& \mathrm{D}$ podem ser diretamente relacionados à capacidade estratégica das firmas. Assim, empresas que realizam gastos com $P \& D$ ambiental em alternativas radicais para novos mercados, como respostas às políticas ambientais, são classificadas como de estratégias inovativas. Em contrapartida, aquelas que apresentam pouco ou nenhum gasto com $P \& D$ ambiental e resistem às pressões ambientais são consideradas de estratégia defensiva (KEMP; ARUNDEL, 1998).

Mas essa discussão não distingue as políticas ambientais por país de origem. A literatura que debate os efeitos ambientais e tecnológicos do Investimento Direto Estrangeiro (IDE) oferece um caminho para discutir as influências políticas ambientais estrangeiras (do país de origem do IDE) no país receptor e as diferentes práticas de gestão ambiental e tecnológica. Por meio do IDE pode ser gerado um efeito tecnológico no país receptor, que compreende desenvolvimento, transferência e difusão de tecnologias ambientais, investimentos em P\&D, mobilidade de mão de obra qualificada e exigências sobre a cadeia de fornecimento (ORGANISATION FOR ECONOMIC CO-OPERATION AND DEVELOPMENT, 2002).

A presença de empresas transnacionais de países desenvolvidos em um país em desenvolvimento pode significar a introdução de tecnologias ambientais mais avançadas e refletir uma atuação das filiais estrangeiras superior à das empresas locais. Por outro lado, também pode representar o uso do país receptor, em geral com um marco regulatório menos rigoroso do que o do país de origem, como um "porto de poluição", caso as transnacionais introduzam tecnologias sujas e obsoletas nas filiais (CHUDNOVSKY; LOPEZ, 1999; ZARSKY, 1999 apud ROCHA, 2006).

A introdução de tecnologias ambientais no país receptor do investimento estrangeiro depende de muitos fatores, mas especialmente da estratégia de gestão ambiental adotada pelos investidores estrangeiros. É possível associar modos de gestão ambiental ao marco regulatório do país receptor ou de origem do investimento. Quando as estratégias são descentralizadas entre matriz e filial, esta última segue suas próprias estratégias, ou opera conforme as regulações ambientais do país hospedeiro, o que caracteriza uma adaptação às políticas ambientais locais. Por sua vez, estratégias centralizadas são aquelas nas quais a companhia adota práticas de gestão vinculadas às da matriz, independentemente do local onde opera. Nesse caso, 
segue-se o marco regulatório do país de origem, pois a regulação no país hospedeiro é vista como insuficiente, ineficiente e custosa para a adequação (HANSEN, 1999).

Caso as forças regulatórias do país receptor sejam frágeis em termos de enforcement, infraestrutura ambiental e pessoal treinado, as transnacionais podem explorar essas diferenças atenuando as medidas ambientais, ou antecipar normas mais rigorosas, introduzindo tecnologias avançadas. As regulações do país de origem, por sua vez, podem ser transmitidas para a filial por intermédio de informações e de assistência técnica. Forças informais, como a pressão de organizações não governamentais (ONGs) e da sociedade local e ações voluntárias das empresas também têm papel importante, sobretudo quando o marco regulatório local é fraco (HANSEN, 1999).

As exigências ambientais externas também podem afetar as relações entre as empresas (fornecedora e compradora, por exemplo) de um setor localizado em determinado país e, portanto, sua organização industrial. A economia institucional pode fornecer uma variável nova nessa discussão.

As transações realizadas no mercado entre os agentes podem se tornar dispendiosas, conforme essa visão. Os custos de transação surgem de fricções que ocorrem nas transferências de bens e serviços por meio de interfaces tecnologicamente separáveis e afetam as relações entre os agentes na cadeia. As principais dimensões da transação são a frequência com que são realizadas (ocasional ou recorrente) e o grau de incerteza da especificidade dos investimentos. A especificidade dos ativos está associada à idiossincrasia das transações e refere-se ao grau no qual um ativo pode ser reempregado em outros usos ou para outros usuários sem perda de valor econômico. Há investimentos específicos quanto à localização, à necessidade de um equipamento especial, a treinamentos especializados, entre outros (WILLIAMSON, 1986, 1987, 1996).

Assim, quanto maiores o grau de especificidade dos ativos, a recorrência da transação e o grau de incerteza, a produção tende a se internalizar para economizar custos de transação e de produção, e a transação será removida do mercado. Modos alternativos de contrato também são previstos, como mostra o Quadro 1. Em contratos bilaterais, por exemplo, a autonomia das partes é mantida e a relação se sustenta pelo risco de perdas com a finalização do contrato. Transações contratuais entre fornecedor e comprador, que envolvem altos e específicos investimentos para a produção de um componente e treinamento dos trabalhadores, tornariam muito custoso o término prematuro da relação. Ou seja, transações específicas e complexas exigem formas mais complexas de organização da produção ou formas contratuais de realizar a transação (WILLIAMSON, 1986, 1987). 
QUADRO 1

Características das transações e tipos de forma contratual

\begin{tabular}{|l|l|l|l|l|}
\hline \multirow{2}{*}{ Frequência } & \multicolumn{3}{c|}{ Investimentos } \\
\cline { 3 - 5 } & Não específicos & Mistos & Idiossincráticos \\
\hline \multirow{2}{*}{} & Ocasional & Mercado & Trilateral & Trilateral \\
\cline { 2 - 5 } & Recorrente & Mercado & Bilateral & Unificada \\
\hline
\end{tabular}

Fonte: Williamson (1986, p. 112).

Entre as principais formas de integração vertical, estão a integração para frente (na distribuição, nas vendas e nos serviços) e para trás (insere fornecedores de materiais brutos para economizar custos de transação). Outro exemplo é a subcontratação de fornecedores de partes, quando esses estão em grande número. Como consequência, a integração realizada por firmas dominantes pode colocar as pequenas empresas rivais em desvantagem estratégica, reduzindo o tamanho do segmento não integrado ou desencorajando a entrada de firmas preparadas pela falta de experiência e pela necessidade de altos custos de capital (WILLIAMSON, 1987).

Embora a tendência das instituições (regras formais, informais e capacidade de fazê-las cumprir) seja a de reduzir os custos de transação facilitando as trocas, algumas instituiçôes - devido ao estabelecimento de regras que restringem a entrada, à inspeção desnecessária ou ao aumento dos custos de informação - acabam por elevá-los. Além disso, uma instituição pode gerar, por exemplo, um aumento desses custos que foram mais do que compensados pela queda dos gastos de transformação (NORTH, 1990, 1992, 1994, 2005).

Sugere-se, nesse sentido, que exigências ambientais externas, que tendem a gerar ou aumentar os custos de transação por se estenderem ao longo da cadeia, podem afetar a relação entre os agentes no setor, tornando mais complexa a organização da produção local.

E do ponto de vista da inserção internacional, o que significaria a adequação a essas exigências? Algumas delas associam-se a níveis de qualidade e a normas ou modelos de comparação, tornando-se padrões de produção aceitos internacionalmente. Também os padrões de produto - que especificam ou definem as características de um produto, como design, tamanho, peso e performance ambiental - podem ser voluntários ou obrigatórios, públicos ou privados e podem afetar os fluxos de comércio de forma positiva e negativa. Teoricamente, os padrões podem ser desejáveis caso favoreçam a compatibilidade de produção em indústrias organizadas 
globalmente (como no setor de tecnologia de informação), reduzam as assimetrias de informação entre compradores e vendedores internacionais e diminuam os danos ao meio ambiente (WORLD TRADE ORGANIZATION, 2005).

Essas três categorias podem representar, por um lado, incremento nos custos de produção, devido às alterações de produto e de processo necessárias para adequação aos padrões, prejudicando certos concorrentes, e, por outro, ganhos advindos da maior participação no mercado internacional.

Essas consideraçóes teóricas permitem estabelecer quatro perguntas para um estudo de caso, levando-se em conta os efeitos das exigências ambientais sobre a empresa e o setor industrial.

Exigências ambientais externas estimulam inovaçôes tecnológicas? De que tipo?

Exigências ambientais externas geram outros efeitos econômicos e ambientais?

Exigências ambientais externas afetam a organização das empresas no setor?

Qual o papel das empresas transnacionais nesse processo?

\section{As exigências ambientais europeias para equipamentos eletroeletrônicos}

Foram promulgadas pela União Europeia, em 2003, e se encontram em vigor, desde 2006, duas exigências para produção e comercialização de equipamentos eletroeletrônicos: a Waste Electrical and Electronic Equipment, conhecida pela sigla WEEE; e a Restriction of the Use of certain Hazardous Substances in Electrical and Electronic Equipment, ou RoHS.

A WEEE visa prevenir e diminuir os resíduos de alguns equipamentos eletroeletrônicos selecionados e amplia a responsabilidade do produtor para as etapas de pós-consumo do produto, como coleta seletiva, tratamento, recuperação, reciclagem e financiamento. Conforme mostra o Quadro 2, a taxa de recuperação desses produtos varia entre $70 \%$ e $80 \%$ do seu peso médio e a taxa de reciclagem, entre $50 \%$ e $75 \%$ do peso médio de eletrodomésticos, produtos de informática e telecomunicaçóes, ferramentas, brinquedos, entre outros. Dessa classificação, excetuam-se produtos empregados na manufatura de outros artigos que não fazem parte dessa diretiva e, temporariamente, os equipamentos médicos (EUROPEAN COMISSION, 2007). 


\section{QUADRO 2}

Taxas de recuperação e reciclagem regulamentadas pela WEEE, segundo categorias de produtos

\begin{tabular}{|l|c|c|}
\hline \multirow{2}{*}{ Categorias de produtos } & \multicolumn{2}{c|}{ Regulamentação WEEE } \\
\cline { 2 - 3 } & $\begin{array}{c}\text { Recuperação } \\
\text { (\% do peso) }\end{array}$ & $\begin{array}{c}\text { Reciclagem } \\
\text { (\% do peso) }\end{array}$ \\
\hline 1- Grandes eletrodomésticos & 80,0 & 75,0 \\
\hline 2- Pequenos eletrodomésticos & 70,0 & 50,0 \\
\hline 3- Tecnologia de informação e telecomunicações & 75,0 & 65,0 \\
\hline 4- Eletrônicos de consumo & 75,0 & 65,0 \\
\hline 5- Equipamentos de iluminação (1) & 70,0 & 50,0 \\
\hline 6- Ferramentas eletroeletrônicas & 70,0 & 50,0 \\
\hline 7- Brinquedos e produtos esportivos & 70,0 & 50,0 \\
\hline 8- Equipamentos médicos & & \\
\hline 9- Equipamentos de controle e monitoramento & - & - \\
\hline 10- Equipamentos de serviço automático & 70,0 & 75,0 \\
\hline
\end{tabular}

Fonte: Official Journal of the European Union (2003) apud European Comission (2008).

(1) Exceto para lâmpadas de descarga de gás, cuja taxa de recuperação mínima é de $80 \%$ do peso da lâmpada.

Já a RoHS objetiva eliminar e/ou reduzir as substâncias perigosas presentes nos equipamentos eletroeletrônicos, tais como chumbo, cádmio, mercúrio, cromo e retardantes de chamas. ${ }^{2}$ Essa exigência é complementar à WEEE, uma vez que substitui substâncias perigosas nos equipamentos eletroeletrônicos por materiais mais seguros, facilitando a reciclagem. São apenas tolerados - em material homogêneo - os valores máximos de $0,01 \%$ por $\mathrm{kg}$ (ou $100 \mathrm{mg} / \mathrm{kg}$ ) para o cádmio e de $0,1 \%$ por $\mathrm{kg}$ (ou $1000 \mathrm{mg} / \mathrm{kg}$ ) para as outras substâncias. Isso se aplica aos equipamentos eletroeletrônicos abrangidos pelas categorias 1, 2, 3, 4, 5, 6, 7 e 10 definidas na WEEE, conforme a primeira coluna do Quadro 2, incluindo as lâmpadas elétricas e os aparelhos de iluminação de uso doméstico (EUROPEAN COMISSION, 2007).

$\mathrm{Na}$ União Europeia, essas exigências são obrigatórias para comercialização e produção de equipamentos eletroeletrônicos, cuja conformidade com as diretivas deve ser comprovada por meio de certificações. Como resultado, tem sido alterada a produção dos países de diferentes regiōes, sendo que muitos vêm adotando legislaçōes similares.

2 As substâncias retardantes de chamas citadas são os bifenis polibromados (PBB) e bifenis polibromados éteres (PBDE). 
A RoHS tem impactos globais independentemente de o país possuir a legislação, gerando inovações tecnológicas - sobretudo decorrentes da substituição do chumbo - e afetando toda a cadeia produtiva.

Os países industrializados já vinham desenvolvendo tecnologias nessa área e são proativos, apesar do registro de aumento nos custos. O Reino Unido realizou gastos com P\&D; o Japão, por exemplo, criou uma rede de inovaçôes para substituição de substâncias perigosas e chegou a registrar mais de 400 patentes por isso (UNITED KINGDOM, 2006; MASARU, 2006). O segmento de componentes dos Estados Unidos também está bem preparado e, embora não existam legislaçóes federais (apenas para alguns estados, como ocorre na Califórnia), uma linha de produção livre de substâncias perigosas tem sido utilizada pelos produtores de vários segmentos não só para a venda externa, como também para a comercialização interna (VELEVA; SETHI, 2004; IMPACT..., 2003).

No entanto, a WEEE tem efeitos localizados nos países que possuem legislações similares e vem estimulando a indústria de reciclagem. Esse é o caso da Noruega e do Japão, cujo esquema transfere a responsabilidade física para esse setor (CHIN-YU; RøINE, 2004; TOJO, 2004). Mas países que não possuem legislações similares podem se tornar alvo da exportação desses resíduos.

Os países asiáticos de industrialização recente, que são os maiores produtores e exportadores de equipamentos eletrônicos, não só apresentaram uma postura reativa, visto que passaram a realizar ajustes no processo produtivo a partir de 2004, mas também desenvolveram algumas inovações por causa da RoHS, como tem sido o caso da China (JIEQIONG; WELFORD; HILLS, 2006). Em países como Tailândia e Filipinas, a RoHS vem sendo transmitida por empresas transnacionais, cuja participação é significativa no setor e, em alguns casos, gerou integração para trás causada pela falta de fornecedores adequados. Um problema desses países refere-se à gestão informal dos resíduos e à sua elevada importação de países desenvolvidos. Como resultado, têm sido estabelecidas legislações similares à RoHS e à WEEE, bem como o controle de importações de resíduos (VOSSENAAR; SANTUCCI; RAMUNGUL, 2006).

A RoHS, a partir da experiência internacional e devido à configuração do setor na forma de indústria global, apresenta efeitos sobre a produção do setor em nível mundial, independentemente de o país possuir legislações similares. Isso indica que essa exigência ambiental tem se tornando um novo padrão de competição para a indústria eletrônica mundial. Esse é um dos motivos pelos quais o foco do estudo de caso para o Brasil recairá sobre a RoHS. A WEEE tem implicações importantes 
por afetar os canais de comercialização dos produtos e dos resíduos em âmbito internacional e por seus estímulos voltados ao setor de reciclagem localizado nos países que estabelecem legislaçôes similares. Um estudo completo requeriria a análise das duas exigências, mas, por questão de ordem, optou-se por focar, inicialmente, os efeitos do ponto de vista da produção de eletrônicos, ou seja, decorrentes da RoHS. A WEEE não será investigada, neste primeiro momento, por envolver uma abordagem de natureza diferenciada, como a investigação de outras atividades econômicas, mas merece ser alvo de estudo de caso particular.

\section{A reação das empresas do complexo eletrônico brasileiro diante da exigência ambiental europeia RoHS}

A fim de facilitar a compreensão dos efeitos da RoHS sobre o complexo eletrônico brasileiro, cumpre traçar as linhas gerais da configuração do setor.

O setor eletroeletrônico é de fundamental importância econômica, pois é altamente dinâmico e inovador e permeia várias atividades produtivas, surgindo na base de outros setores econômicos. ${ }^{3}$ Até meados dos anos 1970, esteve dominado pelas economias desenvolvidas; mas, atualmente, apresenta grande participação dos países asiáticos de industrialização recente. Em termos de organização da produção, o setor se estrutura como uma "rede global de produção" controlada por empresas transnacionais que concentram as atividades de maior valor agregado nas unidades constituintes da corporação (EUA, países da Europa e Japão) e fabricam produtos padronizados por meio da subcontratação em localidades dispersas de baixo custo (países do leste asiático). Entre os ramos produtivos, o segmento de componentes é essencial para a competitividade do setor, porque concentra a tecnologia do produto, agrega valor e apresenta mercado crescente (SÁ, 2004; GOUVEIA, 2004; UNITED NATIONS CONFERATION ON TRADE AND DEVELOPMENT, 2005).

O Brasil representa, nesse contexto, um mercado potente, ${ }^{4}$ mas o complexo eletrônico brasileiro, embora fundamental para o desenvolvimento industrial do

3 O complexo eletrônico, conforme definição usada pelo Banco Nacional de Desenvolvimento Econômico e Social (BNDES), envolve os segmentos de componentes, informática e automação industrial, equipamentos de telecomunicações e eletrônica de consumo. Sua característica fundamental é a produção de bens de mesma base tecnológica (microeletrônica). O setor de equipamentos eletroeletrônicos é mais amplo que o complexo eletrônico, por incluir os ramos de geração, transmissão e distribuição de energia, equipamentos industriais, material elétrico de instalação e serviços de manufatura, conforme informações da Associação Brasileira da Indústria Elétrica e Eletrônica (Abinee). Apesar de em alguns momentos serem utilizadas referências ao setor de equipamentos eletroeletrônicos, visto que tais equipamentos são alvo da diretiva WEEE e RoHS, o foco deste trabalho são os segmentos do complexo eletrônico (GUTIERREZ; ALEXANDRE, 2003).

4 O Brasil esteve entre $011^{\circ}$ e o $12^{\circ}$ maiores mercados nacionais no período de 2002 a 2006 (ELECTRONICS INDUSTRY YEARBOOK, 2005). 
país, apresenta problemas competitivos. A constituição e a evolução do complexo eletrônico brasileiro estiveram associadas, em grande parte, às políticas industriais e ao capital estrangeiro (NASSIF, 2002).

Assim, configura-se, no complexo eletrônico, uma tendência de déficit comercial caracterizado pela importação de componentes - ramo mais dinâmico do setor - e pela exportação de bens finais, em geral, montados no país.

Na década de 1990, com a abertura econômica, o complexo eletrônico brasileiro apresentou aumento do coeficiente de penetração das importações (importações/ consumo aparente), passando de 9\% para 66\% entre 1990 e 2001. Os segmentos mais afetados pela abertura foram os de informática e de componentes, que, com a saída de empresas, tiveram venda reduzida em 60\% em 1992 (NASSIF, 2002). É importante notar a influência das empresas multinacionais no déficit brasileiro do setor na década de 1990, pois as filiais passaram a importar das matrizes, mas os países de origem não se tornaram os principais destinos de suas exportações (GOUVEIA, 2004).

Ao longo dos anos 2000, o saldo comercial total da indústria eletroeletrônica manteve-se negativo em torno de US\$ 10 bilhōes. O segmento de maior exportação é o de telecomunicações, principalmente por causa do aumento da venda de telefones celulares, cujos valores passaram de US\$ 849 milhões para US\$ 2 bilhões, entre 2001 e 2006. Os segmentos de maior importação são o de componentes, cujo valor importado passou de US\$ 6 bilhões em 2001 para US\$ 11 bilhões em 2006, e o de informática, em torno de US\$ 1 bilhão entre 2001 e 2006. Destacam-se as importaçôes de semicondutores, passando de um valor importado de US\$ 1,6 bilhão para US\$ 3,3 bilhões, de componentes para telecomunicações, de US\$ 1 bilhão para US\$2,4 bilhões, e de componentes para informática, de US\$ 889 milhões para US\$ 2 bilhões entre 2001 e 2006 (ASSOCIAÇÃO BRASILEIRA DA INDÚSTRIA ELÉTRICA E ELETRÔNICA, 2007b).

Outro aspecto importante refere-se aos parceiros comerciais. As exportações brasileiras deixaram de ser destinadas principalmente aos EUA - uma vez que sua participação diminuiu de 44\%, em 2001, para 21\%, em 2006 - e passaram a se direcionar aos países da Aladi, cuja participação passou de 35\% para 53\%, nesse mesmo período. A maioria das importações, que eram ofertadas pelos EUA (35\%) e pela UE (25\%) em 2001, passou a se originar dos países do sudeste asiático (62\% em 2006) (ASSOCIAÇÃO BRASILEIRA DA INDÚSTRIA ELÉTRICA E ELETRÔNICA, 2007b). 
Em termos de inovação tecnológica, alguns ramos representativos da indústria eletrônica são classificados como os mais inovativos do país, conforme Tabela 1. A taxa de inovação média desses segmentos, em conjunto, foi superior a 50\% no período 2003-2005, ultrapassando a verificada pela indústria de transformação em geral, que correspondeu a 33,4\% em 2005. Desde 1998 esses segmentos vêm sendo classificados nos níveis de alta e média alta intensidade tecnológica ${ }^{5}$ (INSTITUTO BRASILEIRO DE GEOGRAFIA E ESTATÍSTICA, 2007).

\section{TABELA 1}

Taxas de inovação e incidência sobre a receita líquida, segundo segmentos selecionados Brasil - 2003/2005

Em porcentagem

\begin{tabular}{|c|c|c|c|}
\hline \multirow{2}{*}{ Segmentos selecionados } & \multirow{2}{*}{$\begin{array}{c}\text { Taxas } \\
\text { de inovação }\end{array}$} & \multicolumn{2}{|c|}{$\begin{array}{l}\text { Incidência sobre a receita líquida dos } \\
\text { dispêndios nas atividades }\end{array}$} \\
\hline & & Inovativas & $\begin{array}{l}\text { Internas } \\
\text { de P\&D }\end{array}$ \\
\hline Máq. de escritório e equipamentos de informática & 69,2 & 3,8 & 1,48 \\
\hline Máq., aparelhos e materiais elétricos & 45,7 & 3,5 & 1,29 \\
\hline $\begin{array}{l}\text { Material eletrônico e aparelhos e equipamentos de } \\
\text { comunicações }\end{array}$ & 56,9 & 5,2 & 1,10 \\
\hline $\begin{array}{l}\text { Equipamentos de instrumentação médico- } \\
\text { hospitalares, instrumentos de precisão e ópticos, } \\
\text { equipamentos para automação industrial, } \\
\text { cronômetros e relógios }\end{array}$ & 68,0 & 5,3 & 2,26 \\
\hline
\end{tabular}

Fonte: Instituto Brasileiro de Geografia e Estatística - IBGE. Pintec 2005. Elaboração da autora.

Nesses ramos, as atividades inovativas absorveram entre 3,8\% e 5,3\% da receita líquida de vendas no período e gastaram mais de $1 \%$ da receita líquida com P\&D internos, superando a parcela, como um todo, da receita da indústria destinada a essas atividades e à $\mathrm{P} \& \mathrm{D}(2,8 \%$ e $0,58 \%$ em 2005). Considerando o dispêndio com atividades inovativas em 2003-2005, o gasto com P\&D dos segmentos representou $30 \%$ e aquele realizado com aquisição de máquinas e equipamentos correspondeu

5 Nessa pesquisa do IBGE, foi utilizada a classificação da OCDE, que identifica o grau de intensidade tecnológica dos setores da indústria de transformação e os categoriza em alta (>50\%), média alta (40\%-50\%), média baixa $(<40 \%$, mas acima da média industrial) e baixa tecnologia (< média industrial). O conceito de inovação tecnológica é o sugerido pelo Manual de Oslo (produtos e processos novos ou melhorados) e a taxa de inovação refere-se à participação de inovações realizadas por certos grupos de empresas em relação ao total pesquisado (cerca de 95 mil em 2005). 
a 36\%. O número de empresas que realizaram gastos com P\&D e com aquisição de máquinas e equipamentos, do total de inovadoras, foi, respectivamente, de $46 \%$ e 76\%. Assim, esses ramos não só têm dedicado uma parcela elevada da receita a $\mathrm{P} \& \mathrm{D}$, mas também possuem elevada participação nas aquisições de máquinas. $\mathrm{O}$ principal tipo de inovação desenvolvida foi a de produto; a maioria de inovações de produtos e processos era novidade apenas para a empresa e foi realizada por meio de aprimoramentos (INSTITUTO BRASILEIRO DE GEOGRAFIA E ESTATÍSTICA, 2007).

Portanto, o complexo eletrônico brasileiro encontra fragilidades competitivas nos segmentos mais dinâmicos e, embora seja o mais inovador do país, o setor ainda se encontra à margem da fronteira tecnológica mundial.

\subsection{Metodologia}

O foco da pesquisa foi discutir os efeitos apenas da diretiva RoHS sobre o complexo eletrônico brasileiro, porque esta apresenta impactos mundiais no setor produtor de equipamentos eletroeletrônicos e significa, por isso, um primeiro passo na análise das influências das exigências europeias sobre o Brasil. A pesquisa de campo objetivou levantar dados primários a partir da percepção das empresas e foi realizada por meio de questionários fechados, que foram enviados por correio eletrônico e direcionados a presidentes e diretores das empresas, com o apoio da Associação Industrial. As questões foram elaboradas com base na Pesquisa Industrial de Inovação Tecnológica (Pintec) do Instituto Brasileiro de Geografia e Estatística (IBGE), nos questionários aplicados por outros países e nos indicadores de inovação ambiental discutidos por Kemp e Arundel (1998) e Andersen (2005). Isso permite manter a comparação com outros países e outras pesquisas de inovação no Brasil, bem como o alinhamento de questôes ambientais com o Manual de Oslo.

O universo constituiu-se de 386 empresas selecionadas por meio de dois critérios: representação dos segmentos do complexo eletrônico (automação industrial, telecomunicações, componentes, utilidades domésticas, informática e serviços de manufatura); e participação na Associação Brasileira da Indústria Elétrica e Eletrônica (Abinee). A amostra foi composta por 54 empresas, classificadas por razão social, representando $14 \%$ do universo. Esse tamanho de amostra foi obtido buscando-se a maior precisão estatística possível dentro das restrições de tempo e recursos e da falta de parâmetros sobre a população. ${ }^{6}$ Contudo, o apoio da Associação Industrial

6 A princípio se delineou o tamanho adequado de amostra por meio da estimação de proporções para população 
e o rápido retorno das respostas geradas por profissionais conscientes do problema refletem o alto grau de interesse na pesquisa.

\subsection{Resultados da pesquisa de campo}

Das 54 empresas da amostra, 30 são controladas por capital nacional e 24 por capital estrangeiro originário das regiōes da Europa, América e Ásia. Com relação ao porte das empresas, mais da metade das nacionais classifica-se como pequena e média (PME) e a maioria das estrangeiras é de grande porte (GDE). O principal mercado, em termos de faturamento para a quase totalidade das empresas (92\%) que responderam à questão, é o nacional.

É importante verificar o comportamento das empresas da amostra mediante a nova diretiva europeia, a partir do critério de conformidade. O complexo eletrônico brasileiro tem sido afetado pela diretiva europeia RoHS, pois, do total de empresas pesquisadas, $67 \%$ (36 empresas) estão em conformidade ou em processo de conformidade com a diretiva e $85 \%$ declararam conhecê-la. ${ }^{7}$

Entre as empresas que não estão em conformidade com a diretiva $(33 \%$ da amostra), os principais motivos alegados foram a falta de informação e a não exigência do cliente. ${ }^{8}$ Ressalta-se que $83 \%$ das empresas que não estão adequadas são nacionais; apenas uma empresa estrangeira declarou não conhecer a RoHS.

A análise das empresas adequadas, foco do artigo, foi direcionada no sentido de identificar os tipos dessas empresas, os determinantes da adequação e, especialmente, seus efeitos sobre o processo produtivo.

Com relação às características das empresas adequadas, conforme apontado no Gráfico 1, todos os segmentos são afetados pela diretiva, visto que, da amostra, ao menos duas empresas de cada segmento afirmaram estar em conformidade com a RoHS. O segmento de componentes, mais importante do ponto de vista tecnológico e com elevado grau de competitividade no mundo e no Brasil, destaca-se, seguido pelas empresas do ramo de automação industrial, cuja maioria é de origem nacional.

finita a partir de um grau de confiança de $95 \%$. O erro da estimativa para a amostra final de 54 empresas foi de 12,38\%. Levando-se em conta as dificuldades práticas na realização de amostragem, como a limitação de recursos, a amostra foi considerada razoável (BOLFARINE; BUSSAB, 2005).

7 Para facilitar o texto, as condições "adequadas ou em conformidade com a RoHS" e "em processo de adequação ou de conformidade com a RoHS" serão consideradas na mesma categoria "adequadas ou em conformidade".

8 Três empresas tiveram mais de uma razão para não se adequar, mas os dois principais motivos (falta de informação e falta de exigência do cliente) não foram mencionados simultaneamente por nenhuma empresa. 


\section{GRÁFICO 1}

Empresas da amostra, por segmentos, segundo condição em relação à RoHS (1)

$$
\square \text { Conforme ou em processo de } \quad \square \text { Não conforme }
$$

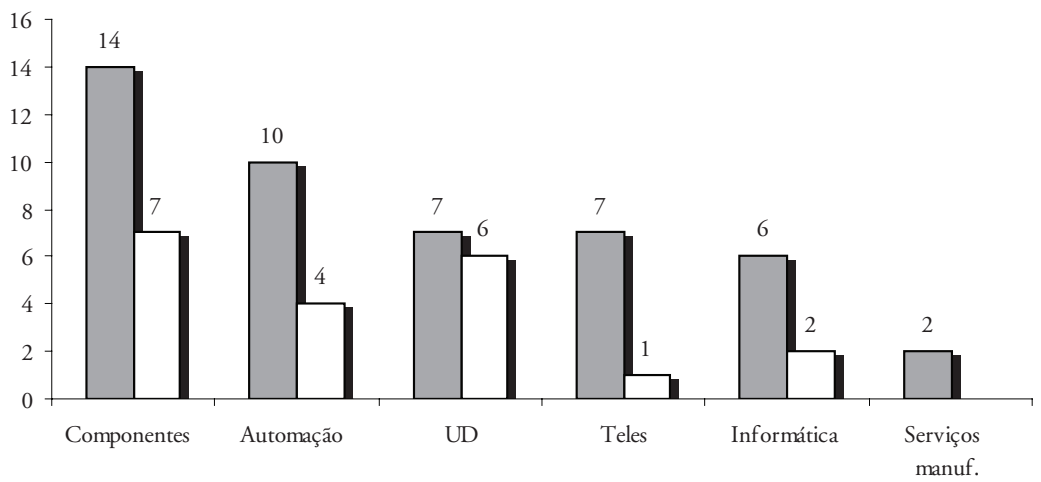

Fonte: Elaboração da autora, a partir das respostas do questionário.

(1) 11 empresas atuam em mais de um segmento.

Em termos de capital de origem, as empresas estrangeiras estão mais avançadas do que as nacionais no que se refere à participação no total de adequadas, ao início do período de ajuste e à informação. Esse fato indica a vinculação das filiais ao marco regulatório do país de origem e a centralização das estratégias ambientais subordinadas às da matriz independentemente da localização da filial. Segundo o Gráfico 2, das 36 empresas que estão em conformidade com a RoHS, 58\% são estrangeiras e $42 \%$, nacionais. Dessas estrangeiras, a maior parte é europeia, seguidas pelas americanas e as japonesas.

\section{GRÁFICO 2}

Distribuição das empresas em conformidade ou em processo de conformidade com a RoHS, segundo origem do capital

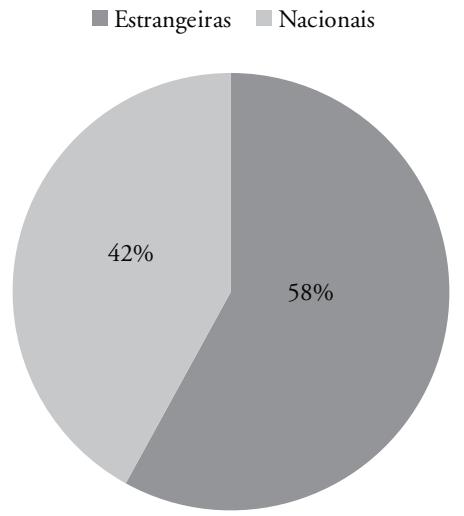

Fonte: Elaboração da autora, a partir das respostas do questionário. 
A maioria das empresas adequadas, em geral, passou a se adequar à RoHS a partir de 2006 (ano de vigência da diretiva) e para menos da metade isso ocorreu entre 2003 e 2006 (Gráfico 3). Além disso, 38\% das empresas adequadas à RoHS, no período 2003-2006, eram estrangeiras e apenas 9\%, nacionais; entre as que iniciaram o processo de adequação após 2006, as nacionais correspondiam a $30 \%$ e as estrangeiras a $23 \%$.

\section{GRÁFICO 3}

Distribuição das empresas, por origem do capital, segundo período de início do processo de conformidade com a RoHS

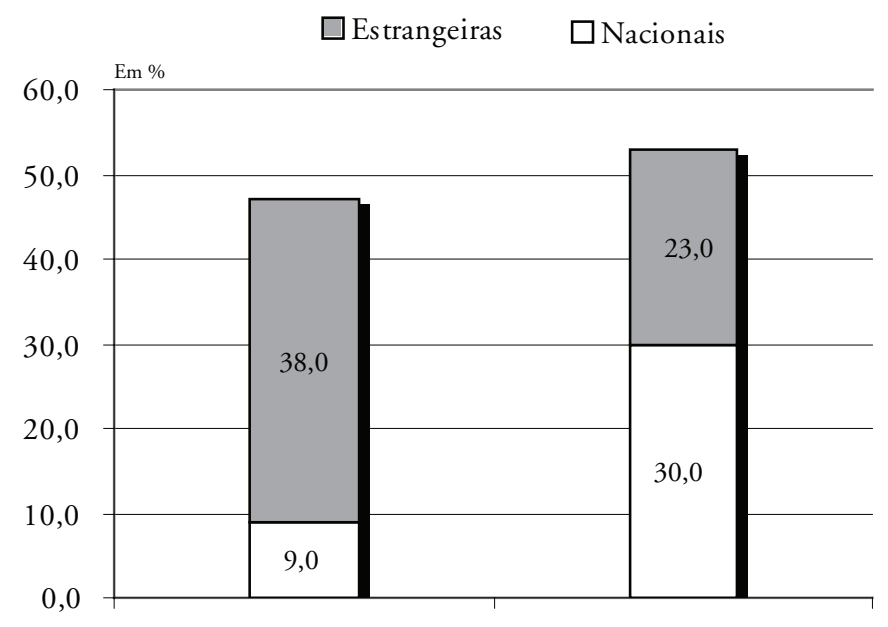

De 2003 a 2006

Após 2006

Fonte: Elaboração da autora, a partir das respostas do questionário.

Para avaliar os fatores determinantes do processo de adequação com a diretiva, investigaram-se as fontes de informação e os motivos para realização da conformidade, além de relacioná-los ao desempenho das empresas transnacionais. De acordo com o Gráfico 4, a principal fonte de informação das empresas adequadas à RoHS foi a matriz, vindo, em seguida, o cliente e conferências, feiras ou encontros. Comparando-se as nacionais e as estrangeiras, a fonte de informação primordial, para estas últimas, foi a matriz, enquanto para as nacionais correspondeu a conferências, clientes e associação industrial. ${ }^{9}$ Quanto às razões de adequação à RoHS, a exigência dos clientes aparece em primeiro lugar, ao se consideram, conjuntamente, as empresas nacionais e as estrangeiras (Gráfico 4). Quando se analisam os resultados separadamente, no entanto, observa-se que, para as estrangeiras, a exigência do cliente e a 
política da matriz foram os principais motivos, enquanto, para as nacionais, foram a conquista de novos mercados, a exigência do cliente e a diferenciação do produto. ${ }^{10}$ Esses resultados apontam quais têm sido os canais de transmissão da diretiva para o setor no Brasil: a demanda e as empresas estrangeiras.

GRÁFICO 4

Empresas, por origem do capital, segundo fontes de informação e motivos de adequação à RoHS
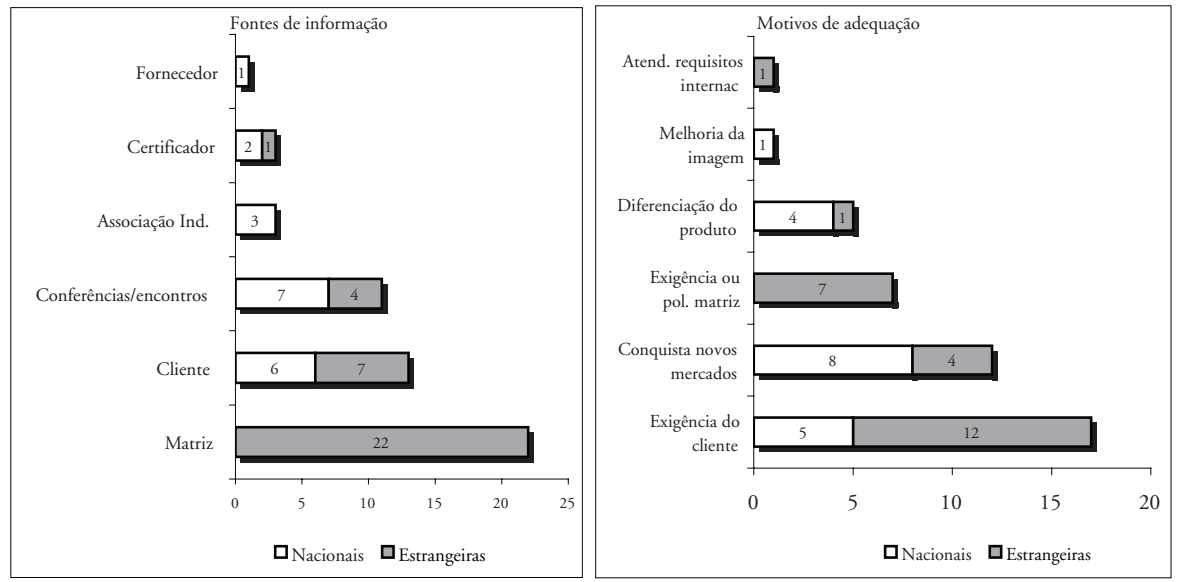

Fonte: Elaboração da autora, a partir das respostas do questionário.

Com vistas a analisar as implicações produtivas decorrentes do processo de adequação à RoHS, foram selecionados três aspectos: efeitos sobre inovação tecnológica; outros efeitos econômicos e ambientais; e aqueles sobre a organização industrial. Ao longo dessa avaliação, distinguem-se empresas nacionais de estrangeiras de modo a captar a influência do marco regulatório do seu país de origem e das práticas de gestão ambiental e tecnológica das matrizes.

Quanto ao primeiro aspecto, avaliou-se a capacidade da RoHS, enquanto um instrumento de política ambiental, de estimular inovações tecnológicas. De acordo com os resultados da pesquisa, o processo de conformidade com a RoHS tem estimulado inovações tecnológicas nas empresas, sendo que as estrangeiras apresentam uma performance tecnológica superior às nacionais nesse processo devido ao apoio da matriz. Conforme o Gráfico 5, do total de empresas adequadas à RoHS, 67\% declararam ter inovado e, entre estas, $62 \%$ eram de capital estrangeiro. ${ }^{11}$

10 Cinco empresas mencionaram mais de um motivo para se adequar à RoHS.

11 Entende-se por inovação tecnológica a mesma definição utilizada na Pintec-IBGE: novos produtos e processos e melhores produtos e processos (INSTITUTO BRASILEIRO DE GEOGRAFIA E ESTATísTICA, 2007). Para essa questão, 15 empresas apontaram mais de um tipo de mudança tecnológica. 
GRÁFICO 5

Proporção de empresas adequadas à RoHS que inovaram e origem do capital dessas empresas
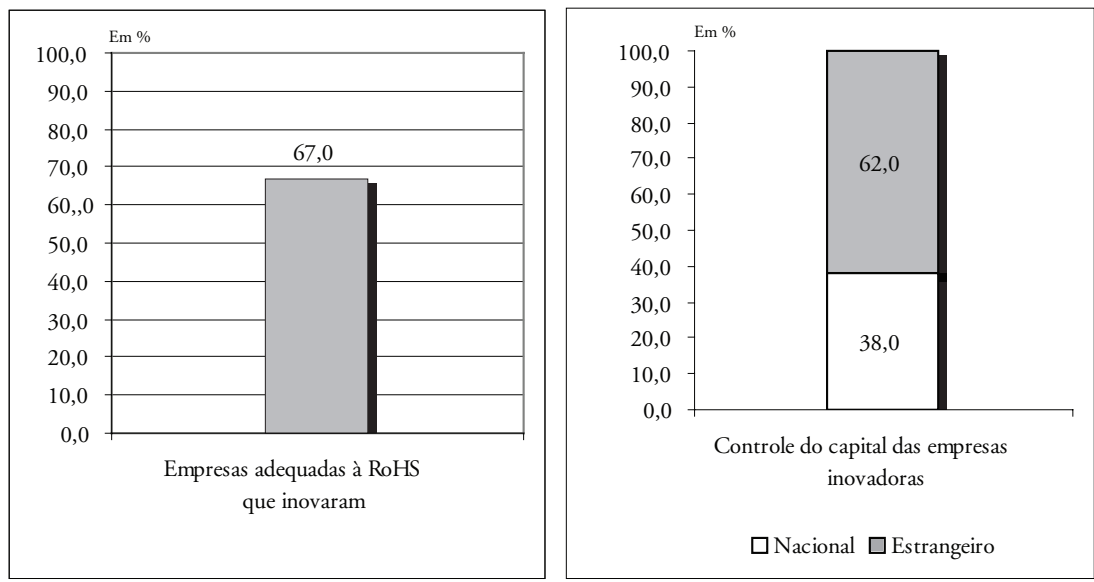

Fonte: Elaboração da autora, a partir das respostas do questionário.

O principal tipo de inovação resultante foi de processo, com 53\% das empresas adequadas, seguido por inovações de produto (36\%) e inovações de produto e processo $(22 \%)$. Nota-se que, das inovações de produto e de processo, a maioria foi desenvolvida por empresas estrangeiras.

As inovações mais significativas constituíram-se de melhorias de processo, enquanto a minoria desenvolveu novos produtos (Gráfico 6). Mudanças de processo podem estar associadas às dificuldades de substituição de materiais perigosos - principal obstáculo apontado por $60 \%$ das empresas adequadas - e significar que a redução de substâncias perigosas é complexa. ${ }^{12}$

As grandes empresas estrangeiras, como indica a Tabela 2, apresentaram níveis elevados de novidade nas inovações, pois tiveram participação acentuada nos novos produtos e processos desenvolvidos. Já as nacionais, sobretudo as de pequeno e médio portes, intensificaram seus esforços nas melhorias de processo.

As atividades inovativas mais registradas foram gastos com $\mathrm{P} \& \mathrm{D}$, treinamento e aquisição de máquinas e equipamentos (Tabela 3). No primeiro item, 57\% das empresas adequadas despenderam com P\&D internos. A matriz também desempenhou papel importante na transferência de P\&D para as empresas estrangeiras. Em segundo lugar, a realização de treinamento foi essencial para $42 \%$ das empresas.

12 De fato, essa também foi a maior dificuldade enfrentada pelas empresas localizadas em outros países como Reino Unido, Noruega, China e Tailândia, especialmente no que se refere à substituição do chumbo (UNITED KINGDOM, 2006; CHIN-YU; RØINE, 2004; JIEQIONG; WELFORD; HILLS, 2006; VOSSENAAR; SANTUCCI; RAMUNGUL, 2006). 
Por fim, 36\% das empresas apontaram a aquisição de máquinas e equipamentos. É também interessante notar que, de todas as empresas que responderam à questão, muitas associaram gastos com treinamento de pessoal à aquisição de máquinas.

\section{GRÁFICO 6}

Proporção de empresas adequadas à RoHS, segundo mudanças tecnológicas de produto e processo

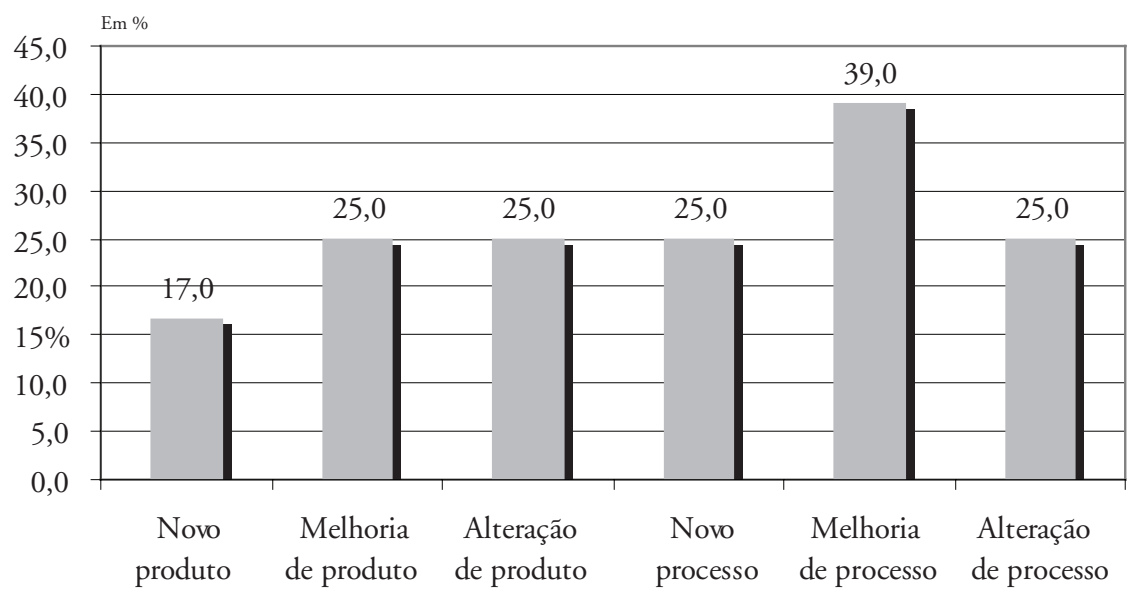

Fonte: Elaboração da autora, a partir das respostas do questionário.

TABELA 2

Empresas adequadas à RoHS, por origem do capital e porte, segundo tipos de mudança tecnológica

\begin{tabular}{l|c|c|c|c|c}
\hline \multirow{2}{*}{ Tipos de mudança tecnológica } & \multicolumn{2}{|c|}{ Nacional } & \multicolumn{2}{c|}{ Estrangeira } & \multirow{2}{*}{ Total } \\
\cline { 2 - 5 } & $\begin{array}{c}\text { Pequeno } \\
\text { e médio } \\
\text { portes }\end{array}$ & $\begin{array}{c}\text { Grande } \\
\text { porte }\end{array}$ & $\begin{array}{c}\text { Pequeno } \\
\text { e médio } \\
\text { portes }\end{array}$ & $\begin{array}{c}\text { Grande } \\
\text { porte }\end{array}$ & 6 \\
\hline Novo produto & 1 & 1 & - & 4 & 9 \\
\hline Melhoria de produto & 1 & 2 & 1 & 5 & 9 \\
\hline Alteração de produto & 3 & - & 3 & 3 & 9 \\
\hline Novo processo & 3 & - & - & 6 & 14 \\
\hline Melhoria de processo & 4 & 2 & 2 & 4 \\
\hline Alteração de processo & 2 & 1 & 2 & 9 \\
\hline
\end{tabular}

Fonte: Elaboração da autora, a partir das respostas do questionário. 
TABELA 3

Empresas adequadas à RoHS, por origem do capital, segundo atividades inovativas para adequação à RoHS

\begin{tabular}{|c|c|c|c|c|c|c|c|c|}
\hline \multirow[b]{2}{*}{ Atividades inovativas } & \multicolumn{3}{|c|}{ Nacional (15) } & \multicolumn{3}{|c|}{ Estrangeira (21) } & \multicolumn{2}{|c|}{ Total (36) } \\
\hline & N.abs. & $\begin{array}{c}N / 36 \\
(1) \\
(\%)\end{array}$ & $\begin{array}{c}\mathrm{N} / \mathrm{T}(2) \\
(\%)\end{array}$ & N. abs. & $\begin{array}{c}E / 36(3) \\
(\%)\end{array}$ & $\begin{array}{c}E / T(4) \\
(\%)\end{array}$ & N. abs. & $\begin{array}{c}T / 36 \\
(5) \\
(\%) \\
\end{array}$ \\
\hline $\begin{array}{l}\text { Compra de máquinas e } \\
\text { equipamentos }\end{array}$ & 6 & 17,0 & 46,0 & 7 & 20,0 & 54,0 & 13 & 36,0 \\
\hline $\begin{array}{l}\text { Gastos com P\&D } \\
\text { internos voluntários }\end{array}$ & 7 & 20,0 & 42,0 & 10 & 28,0 & 58,0 & 17 & 47,0 \\
\hline $\begin{array}{l}\text { Gastos com P\&D } \\
\text { internos compulsórios } \\
\text { (Lei de Informática) }\end{array}$ & 2 & 5,0 & 100,0 & 0 & 0,0 & 0,0 & 2 & 5,0 \\
\hline $\begin{array}{l}\text { Transferência de P\&D } \\
\text { da matriz }\end{array}$ & - & - & - & 8 & 22,0 & - & 8 & 22,0 \\
\hline $\begin{array}{l}\text { Transferência } \\
\text { de tecnologia } \\
\text { ou máquinas e } \\
\text { equipamentos da } \\
\text { matriz }\end{array}$ & - & - & - & 4 & 11,0 & - & 4 & 11,0 \\
\hline Registro de patentes & 0 & 0,0 & 0,0 & 0 & 0,0 & 0,0 & 0 & 0,0 \\
\hline Treinamento de pessoal & 5 & 14,0 & 33,0 & 10 & 28,0 & 67,0 & 15 & 42,0 \\
\hline $\begin{array}{l}\text { Cooperação com } \\
\text { empresas fora do } \\
\text { grupo }\end{array}$ & 3 & 8,0 & 50,0 & 3 & 8,0 & 50,0 & 6 & 17,0 \\
\hline $\begin{array}{l}\text { Associação com } \\
\text { instituições de } \\
\text { pesquisa/universidades }\end{array}$ & 2 & 5,0 & 67,0 & 1 & 3,0 & 33,0 & 3 & 8,0 \\
\hline
\end{tabular}

Fonte: Elaboração da autora, a partir das respostas do questionário.

(1) N/36: participação de empresas nacionais no total de empresas adequadas à RoHS.

(2) N/T: participação de empresas nacionais por atividade inovativa.

(3) E/36: participação de empresas estrangeiras no total de empresas adequadas à RoHS.

(4) E/T: participação de empresas estrangeiras por atividade inovativa.

(5) T/36: participação do item no total das empresas adequadas à RoHS.

De acordo com a Tabela 4, das 23 empresas que afirmaram realizar algum tipo de dispêndio com P\&D para adequação à RoHS (seja este interno voluntário, compulsório ou transferido da matriz), a maioria gastou menos de $2,5 \%$ do custo total com $\mathrm{P} \& \mathrm{D}$ e nenhuma despendeu mais de $10 \%$ da despesa total com P\&D. A maior parte das empresas que empregaram menos de $2,5 \%$ é estrangeira e, das que gastaram entre $2,5 \%$ e $5 \%$, a maioria é nacional.

Em praticamente todas as atividades inovativas mencionadas como as mais indicadas para adequação à RoHS, a participação das estrangeiras foi superior à das nacionais. Como se pode observar, as empresas estrangeiras desfrutam da aju- 
da da matriz. De acordo com a Tabela 3, as estrangeiras declararam realizar mais da metade das ações direcionadas ao treinamento, aos gastos com P\&D internos voluntários e à aquisição de máquinas e equipamentos. Além disso, 12 empresas receberam transferências da matriz na forma de $\mathrm{P} \& \mathrm{D}$ e de tecnologias ou máquinas e equipamentos, o que significa 33\% do total das empresas adequadas e $57 \%$ do total de estrangeiras adequadas.

De outro lado, destacaram-se a fraca associação com universidades e instituições de pesquisas, a pouca cooperação com empresas fora do grupo e nenhum registro de patentes.

TABELA 4

Empresas adequadas à RoHS, por origem do capital, segundo faixas de gastos com P\&D para adequação à RoHS

\begin{tabular}{|c|c|c|c|c|c|c|}
\hline \multirow[b]{2}{*}{ Faixas de gastos com P\&D } & \multicolumn{2}{|c|}{ Nacional } & \multicolumn{3}{|c|}{ Estrangeira } & \multirow{2}{*}{$\begin{array}{c}\text { Total } \\
\text { T/23 (3) } \\
(\%)\end{array}$} \\
\hline & N. abs. & $\begin{array}{c}N / 23(1) \\
(\%)\end{array}$ & N. abs. & $\begin{array}{c}E / 23(2) \\
(\%)\end{array}$ & N. abs. & \\
\hline $\begin{array}{l}\text { Menos de } 2,5 \% \text { do gasto total com } \\
\text { P\&D }\end{array}$ & 5 & 22,0 & 12 & 52,0 & 17 & 74,0 \\
\hline $\begin{array}{l}\text { De } 2,5 \% \text { a } 5 \% \text { do gasto total com } \\
\text { P\&D }\end{array}$ & 3 & 13,0 & 1 & 4,3 & 4 & 17,0 \\
\hline $\begin{array}{l}\text { De } 5 \% \text { a } 10 \% \text { do gasto total com } \\
\text { P\&D }\end{array}$ & 1 & 4,3 & 1 & 4,3 & 2 & 9,0 \\
\hline Mais de $10 \%$ do gasto total com P\&D & - & - & - & - & - & - \\
\hline
\end{tabular}

Fonte: Elaboração da autora, a partir das respostas do questionário.

(1) N/23: participação de empresas nacionais no total de empresas adequadas que responderam a questão.

(2) E/23: participação de empresas estrangeiras no total de empresas adequadas que responderam a questão.

(3) T/23: participação do item no total das empresas adequadas que responderam a questão.

Num outro aspecto, avaliou-se se os esforços inovativos decorrentes do processo de conformidade com a RoHS geram efeitos econômicos e ambientais compensatórios. A Tabela 5 sintetiza esses resultados. Os impactos econômicos destacados foram a melhoria da qualidade ou o aumento da durabilidade do produto, a alta do custo total e a elevação do preço do produto. Já os impactos ambientais mais mencionados foram o crescimento no uso de insumos e materiais e a maior facilidade de reciclagem do produto. $\mathrm{O}$ aumento do consumo de energia e do faturamento significou metade das respostas indicadas, e outros impactos não foram conclusivos, como os ganhos ou perdas comerciais. ${ }^{13}$

13 Nem todas as 36 empresas adequadas puderam indicar os efeitos e estimar sua variação média percentual, pois muitas ainda estão em fase de estudos. 
TABELA 5

Empresas adequadas à RoHS, por origem do capital, segundo os principais impactos econômicos e ambientais mencionados

\begin{tabular}{|c|c|c|c|c|c|c|c|}
\hline \multirow{2}{*}{$\begin{array}{c}\text { Impactos } \\
\text { econômicos } \\
\text { e ambientais }\end{array}$} & \multicolumn{3}{|c|}{ Nacional } & \multicolumn{3}{|c|}{ Estrangeira } & \multirow{2}{*}{$\begin{array}{l}\mathrm{N}^{\circ} \text { de } \\
\text { respostas }\end{array}$} \\
\hline & $\begin{array}{l}\text { Impacto } \\
\text { maior }\end{array}$ & $\begin{array}{l}\text { Impacto } \\
\text { menor }\end{array}$ & Nulo & $\begin{array}{l}\text { Impacto } \\
\text { maior }\end{array}$ & $\begin{array}{l}\text { Impacto } \\
\text { menor }\end{array}$ & Nulo & \\
\hline $\begin{array}{l}\text { Qualidade ou } \\
\text { durabilidade do } \\
\text { produto }\end{array}$ & 4 & 1 & - & 11 & - & $2 s$ & 18 \\
\hline Preço & 8 & 1 & - & 9 & 1 & 4 & 23 \\
\hline Produtividade & 1 & 3 & 1 & 4 & 2 & 5 & 16 \\
\hline Exportação & 3 & 5 & - & 3 & 2 & 4 & 17 \\
\hline Importação & - & 2 & 1 & 5 & 1 & 4 & 13 \\
\hline Faturamento & 2 & 1 & 1 & 5 & 1 & 4 & 14 \\
\hline Custo total & 6 & - & - & 12 & 2 & 3 & 23 \\
\hline $\begin{array}{l}\text { Consumo de } \\
\text { energia }\end{array}$ & 3 & - & 1 & 4 & 1 & 5 & 14 \\
\hline $\begin{array}{l}\text { Uso de insumos ou } \\
\text { materiais }\end{array}$ & 4 & - & 1 & 9 & 1 & 3 & 18 \\
\hline $\begin{array}{l}\text { Emissão de } \\
\text { poluentes }\end{array}$ & 1 & 3 & - & 2 & 4 & 5 & 15 \\
\hline $\begin{array}{l}\text { Facilidade de } \\
\text { reciclagem }\end{array}$ & 3 & 1 & - & 10 & - & 3 & 17 \\
\hline $\begin{array}{l}\text { Gastos com } \\
\text { transporte/descarte } \\
\text { de resíduos }\end{array}$ & - & 2 & - & 6 & - & 6 & 14 \\
\hline
\end{tabular}

Fonte: Elaboração da autora, a partir das respostas do questionário.

$\mathrm{Na}$ esfera da organização industrial, testou-se a possibilidade de os custos de transação, decorrentes do processo de conformidade com a RoHS, alterarem os modos de relação contratual entre os agentes da cadeia. Nesse sentido, a pesquisa apontou que a RoHS tem afetado as relações entre as empresas do complexo brasileiro, pois, do total das adequadas, $56 \%$ afirmaram ter suas relações de compra e venda afetadas pela RoHS e 36\% mencionaram não sentir alterações nas relações com fornecedores ou clientes. ${ }^{14}$ De acordo com o Gráfico 7 , um número razoável de respostas indicou impactos para trás na cadeia, mas isso não chegou a constituir integração vertical para nenhuma empresa. Desse total de empresas adequadas cujas relaçôes foram afetadas, as respostas sinalizaram que a maioria tem realizado gestão 
da cadeia de fornecimento, firmado contratos com fornecedores especializados e reduzido o número de fornecedores.

Esse resultado coincide com o segundo principal obstáculo declarado por $48 \%$ das empresas adequadas: a falta de fornecedores tecnológica e ambientalmente adequados.

GRÁFICO 7

Empresas adequadas à RoHS, por origem do capital, segundo tipos de impacto da RoHS sobre a organização industrial

$\square$ Nacionais $\square$ Estrangeiras

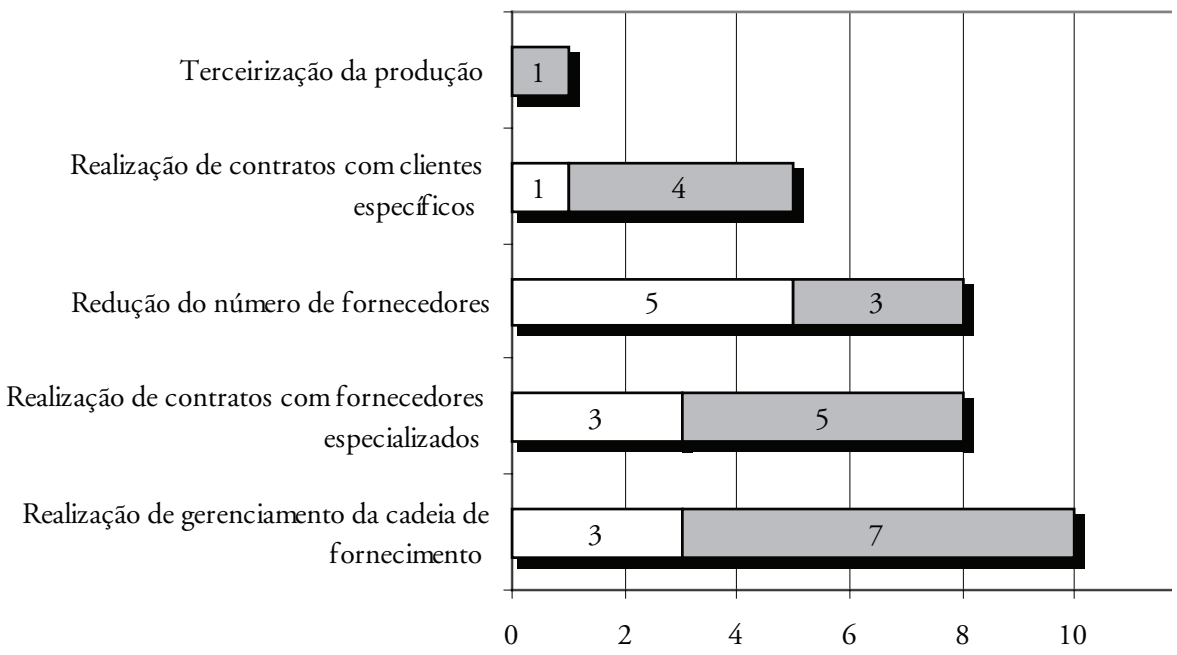

Fonte: Elaboração da autora, a partir das respostas do questionário.

\section{Considerações finais}

O objetivo deste artigo foi avaliar as implicações das exigências ambientais europeias sobre o complexo eletrônico no Brasil, um dos mais importantes do ponto de vista de encadeamentos tecnológicos e de geração do PIB industrial, com base nas reflexôes teóricas da economia industrial.

Verificou-se que, apesar de o complexo eletrônico brasileiro ter baixa participação no mercado mundial, caracterizar-se como um importador líquido de produtos ligados aos segmentos de partes e componentes e realizar pouco comércio com a UE, a maioria das empresas em operação no Brasil encontra-se em conformidade com uma exigência europeia que proíbe a importação de equipamentos que conte- 
nham certos níveis de substâncias perigosas. A experiência internacional mostra que essa exigência tem afetado a indústria eletroeletrônica mundial, visto que o setor produtivo de vários países vem realizando ajustes para cumpri-la.

Os principais canais de transmissão dessa medida no Brasil têm sido a exigência dos clientes e a atuação de empresas estrangeiras, uma vez que a maior parte daquelas que se encontram em conformidade com a RoHS no país é controlada por capital estrangeiro. Esse fato sinaliza que as estratégias dessas empresas estão vinculadas às das matrizes, ou seja, encontram-se alinhadas às das matrizes e não estão associadas ao marco regulatório local. $\mathrm{O}$ Brasil não possui medidas semelhantes do ponto de vista de política ambiental até o momento e, como os resultados sugerem, o país não tem sido utilizado como "porto de poluição".

Outros estudos realizados no Brasil não são consensuais quanto à performance ambiental de empresas estrangeiras. De um lado, verificou-se que as paulistas de maior inserção internacional (aquelas cujo controle do capital é estrangeiro ou são exportadoras) são as mais preocupadas com o meio ambiente (LUSTOSA, 1999). Mas, de outro lado, em estudos de caso setoriais, a origem do capital não foi o fator determinante do comportamento ambiental na indústria petroquímica (ALMEIDA, 2001), e as empresas nacionais do setor de papel e celulose estão à frente das estrangeiras quanto à gestão ambiental (ROCHA, 2006).

A medida ambiental europeia RoHS também tem impactos inovadores, e as empresas estrangeiras apresentaram performances tecnológicas superiores devido ao auxílio que recebem da matriz. Inovações incrementais de processo foram os principais resultados gerais (independentemente da origem do capital) em termos de inovação tecnológica, mas novos produtos e processos foram as principais respostas das estrangeiras. Uma nova exigência de produto, portanto, tem gerado alteraçôes de processo, pois a mudança tecnológica relacionada à substituição de insumos no produto é mais complexa do que se pensa. Apesar do rigor da RoHS, inovação incremental é um resultado coerente, visto que a exigência não é obrigatória no Brasil. Mas, em termos de estratégias competitivas, o complexo eletrônico parece se comportar de forma reativa, porque a maioria das empresas vem se adequando apenas recentemente e se alijando desse nicho de comércio sustentável.

Nas atividades inovativas, os principais indicadores registrados foram aquisição de máquinas e equipamentos e gasto com $\mathrm{P} \& \mathrm{D}$. Em valores, a despesa com $\mathrm{P} \& \mathrm{D}$ para adequação à RoHS encontra-se abaixo de $2,5 \%$ do gasto total das empresas com P\&D. Considerando-se que o setor no Brasil é o que mais investe em P\&D em porcentagem do faturamento - acima da média industrial - e que o Reino Unido 
tem despendido, para esse fim, cerca de 5\% de seu gasto total com P\&D, esse foi um dispêndio relativamente baixo (INSTITUTO BRASILEIRO DE GEOGRAFIA E ESTATÍSTICA, 2007; UNITED KINGDOM, 2006).

De fato, as evidências empíricas sugerem, em termos dos efeitos inovadores de política ambiental, uma forte associação com o padrão de concorrência setorial, com o ambiente institucional e com as políticas necessárias para melhorar as competências específicas das empresas (LUSTOSA, 2003).

Quanto à origem do capital, o apoio da matriz se reflete nas transferências de P\&D, de máquinas e equipamentos para as filiais localizadas no Brasil, estabelecendo uma performance tecnológica superior por parte das empresas estrangeiras no que tange aos efeitos inovadores da diretiva europeia.

Esse resultado pode associar-se à concentração das atividades tecnológicas e de inovação nos países industrializados. Evidências apontam que, a partir de dados sobre gastos em P\&D, patentes, receitas de royalties, entre outros, o mercado internacional de tecnologia está dominado por um grupo de países industrializados, sendo que a atividade tecnológica desses países está concentrada em um grupo de corporações (KUMAR, 1997).

Quanto à organização industrial, a RoHS exige a conformidade de produtores de bens finais, mas tem se estendido para trás ao longo da cadeia. Em razão da necessidade (e da carência) de fornecedores especializados, têm sido realizados acordos exclusivos, semelhantes aos contratos bilaterais ou trilaterais. Uma consequência importante desse novo tipo de relação seria a limitação da competição, sobretudo por meio da exclusão de fornecedores pequenos e médios (menos concentrados), ou da importação via relações matriz-filial.

Esses resultados denotam uma contribuição prática do estudo empírico. A exigência ambiental RoHS impõe novos desafios competitivos ao complexo eletrônico brasileiro, uma vez que o descumprimento da diretiva evita potenciais ganhos de competitividade para os segmentos mais intensivos em tecnologia do complexo e tende a acentuar a distância entre empresas nacionais e estrangeiras quanto à performance tecnológica e à participação no comércio internacional. Além desses, pode ser configurada uma tendência ao encurtamento de outros elos da cadeia de equipamentos eletroeletrônicos.

Da ótica teórica, a pesquisa contribui para a discussão das barreiras técnicas às exportações por meio de elementos da economia industrial, além de ser útil para ressaltar a importância do desenvolvimento de indicadores de inovação ambiental alinhados com a metodologia da Pintec e, portanto, do Manual de Oslo. 
O levantamento também coloca questôes do ponto de vista político, no que toca os rumos das instituiçôes ambientais e de ciência e tecnologia no Brasil. Duas merecem discussão: a necessidade do desenvolvimento de políticas auxiliares de infraestrutura de ciência e tecnologia para as empresas do complexo eletrônico; e a demanda por implantação, no Brasil, de medidas ambientais similares às europeias.

As limitações do estudo se encontram, principalmente, em lacunas que devem ser cobertas por meio de pesquisas complementares. Uma delas seria a avaliação dos impactos, no Brasil, da exigência que trata de resíduos de equipamentos eletroeletrônicos (WEEE). Outra refere-se à abordagem de aspectos mais amplos associados às exigências ambientais externas, que ultrapassam o nível produtivo e o da organização industrial. A capacitação dos organismos envolvidos no processo de conformidade dos produtos com as exigências externas, como agências de avaliação da conformidade e organizações certificadoras, institutos de pesquisa, laboratórios de testes, entre outros, é fundamental para o acesso ao mercado externo.

\section{Referências bibliográficas}

ALMEIDA, L. T. Harmonização internacional de regulaçōes ambientais: um estudo da petroquímica brasileira. 2001. Tese (Doutorado em Economia) - Instituto de Economia, Universidade Estadual de Campinas, Campinas, 2001.

ANDERSEN, M. M. Eco-innovation indicators. In: ECO INNOVATION INDICATORS WORKSHOP, 2005, Copenhagen. Workshop background papers... Copenhagen: EEA, 2005, p. 1-28. Disponível em: <http://technologies.ew.eea.europa.eu/resources/case_studies/conferences/innovation_indicator_29_09_05/ei_background.pdf >. Acesso em: 13 ago. 2008. ASSOCIAÇÃO BRASILEIRA DA INDÚSTRIA ELÉTRICA E ELETRÔNICA [ABINEE]. Disponível em: <http:www.abinee.org.br>. Acesso em: 03 fev. 2008.

Panorama econômico e desempenho setorial 2007. 2007a. Disponível em: $<$ http:www.abinee.org.br>. Acesso em: 03 fev. 2008. . Comportamento da indústria eletroeletrônica $1^{\circ}$. semestre de 2007. $2007 \mathrm{~b}$.

BOLFARINE, H.; BUSSAB, W. O. Elementos de amostragem. São Paulo: Edgard Blücher, 2005.

CHIN-YU, L.; RØINE, K. Extended producer responsibility stimulating technological changes and innovation: case study in the Norwegian electrical and electronic industry. Rapport, Trondheim, n.1, p. 1-49, 2004. Disponível em: <http://ntnu.diva-portal.org/smash/ record.jsf.pid=diva2:126157>. 
CHUDNOVSKY, D.; LOPEZ, A. TNCs and the diffusion of environmentally friendly technologies to developing countries. [s.1.]: UNCTAD/CBS, 1999 (Occasional Paper, n.9). Disponível em: <http://openarchive.cbs.dk/bitstream/handle/10398/6946/chudnovsky.pdf?sequence=1>. Acesso em: 23 jul. 2007.

DOSI, G. Technological paradigms and technological trajectories: a suggested interpretation of the determinants and directions of technical change. Research Policy, Amsterdan, v. 11, n. 3, p. 147-162, 1982.

ELECTRONICS INDUSTRY YEARBOOK 2005 EDITION. Reed Electronics Group. Disponível em: <http://redigitaleditions.com>. Acesso em: 09 nov. 2007.

EUROPEAID. Estudo setorial eletroeletrônico. Projeto Rede de Centros Tecnológicos, Relatório Final, 2006.

EUROPEAN COMISSION [EC]. Disponível em: <http:www.ec.europa.eu>. Acesso em: 10 maio 2007.

GOUVEIA, F. O papel das subsidiárias brasileiras na nova configuração das corporaçôes multinacionais: um estudo com base na indústria eletrônica. 2004. 272 p. Dissertação (Mestrado em Economia) - Instituto de Economia, Universidade Estadual de Campinas, Campinas, 2004.

GUTIERREZ, R. M. V.; ALEXANDRE, P. V. M. Complexo eletrônico brasileiro e competitividade. BNDES Setorial, Rio de Janeiro, n. 18, p. 165-192, set. 2003.

HANSEN, M. W. Cross border environmental management in transnational corporations: an analytical framework. [s.l.]: UNCTAD/CBS, 1999 (Occasional Paper, n.5). Disponível em: <http://openarchive.cbs.dk/bitstream/handle/10398/7010/occasional\%20paper\%205. pdf?sequence=1>. Acesso em: 23 jul. 2007.

IMPACT of RoHS on electronic products sold in United States. INFORM: strategies for a better environment, New York, p.1-4, september 2003. Disponível em: <www.informinc. org/impRohs.pdf>. Acesso em: 23 de jun. 2007.

INSTITUTO BRASILEIRO DE GEOGRAFIA E ESTATÍSTICA [IBGE]. Pesquisa Industrial Inovação Tecnológica (Pintec-2005). Rio de Janeiro: IBGE, 2007.

JIEQUIONG, Y.; WELFORD, R.; HILLS, P. Industry responses to EU WEEE and ROHS Directives: perspectives from China. Corporate Social Responsibility and Environmetal Management, Thailand, v. 13, n. 5, p. 286-299, 2006.

KEMP, R; SOETE, L. Inside the "green box": on the economics of technological change and the environment. In: FREEMAN, C.; SOETE, L. (Eds.). New explorations in the economics or technological change. London: Pinter Publishers, 1990, p. 245-257. 
KEMP, R.; ARUNDEL, A. Survey indicators for environmental innovation. IDEA: Paper series, n.8, p.1-30, 1998. Disponível em: <http://www.step.no/old/Projectarea/IDEA/Idea8. pdf>. Acesso em: 10 abr. 2009.

KUMAR, N. Technology generation and technology transfers in the world economy: recent trends and implications for developing countries. INTECH: discussion papers series, Netherlands, p.1-35, september 1997. Disponível em: <http://www.intech.unu.edu/publications/ discussion-papers/9702.pdf>. Acesso em: 05 nov. 2007.

LUSTOSA, M. C. Inovação e meio ambiente no enfoque evolucionista: o caso das empresas paulistas. In: ENCONTRO NACIONAL DA ANPEC, 27, 1999, Belém. Anais... Belém: Anpec, 1999. Disponível em: <http://www.ie.ufrj.br/gema/dcie_publicacoes. php?filtroano=1999>. Acesso em: 19 mar. 2007.

LUSTOSA, M. C. J.; CÁNEPA, E. M.; YOUNG, C. E. F. Política ambiental. In: MAY, P. H., LUSTOSA, M. C.; VINHA, V. (Orgs.). Economia do meio ambiente: teoria e prática. Rio de Janeiro: Elsevier, 2003, p. 135-153.

NASSIF, A. O complexo eletrônico brasileiro. In: BNDES (Org.). BNDES 50 anos: histórias setoriais. Rio de Janeiro, Dórea Books and Arts, 2003. Disponível em <http://www. bndes.gov.br/SiteBNDES/export/sites/default/bndes_pt/Galerias/Arquivos/conhecimento/ livro_setorial/setorial08.pdf>. Acesso em: 15 ago. 2007.

NELSON, R. R.; WINTER, S. G. An evolutionary theory of economic change. Cambridge: Belknap Press of Harvard University Press, 1982.

NORTH, D. Institutions, institutional change and economic performance. Cambridge: University Press, 1990.

. Custos de transação, instituições e desempenho econômico. Tradução de Elizabete

Hart. Rio de Janeiro: Instituto Liberal, 1992.

. Economic performance through time. American Economic Review, Cambridge, v. 84, n.3, p. 359-368, june 1994.

. Institutions and the performance of economies over time. In: MENARD, C.; SHIRLEY, M. (Eds.). Handbook of new institutional economics. Dordrecht: Springer, 2005, p. $21-30$.

ORGANISATION FOR ECONOMIC CO-OPERATION AND DEVELOPMENT [OCDE]. Environmental policies: technology effects. In: Technology and environment: towards policy integration. Paris, 1999, p 4-24. Disponível em: <http://www.oecd.org/ dataoecd/58/2/1898311.pdf>. Acesso em: 12 ago. 2008.

. Environmental benefits of foreign direct investment: a literature review. Paris: OECD, 2002. Working Party on global and structural policies. Disponível em: <http:// 
www.oecd.org/officialdocuments/displaydocumentpdf/?cote=env/epoc/gsp(2001)10/ final\&doclanguage=en>. Acesso em: 12 ago. 2007.

PORTER, M. E.; VAN DER LINDE, C. Towards a new conception of the environment - competitiveness relationship. Journal of Economic Perspectives, Nashville, v. 9, n. 4, p. 97-118, 1995.

ROCHA, S. S. Sustentabilidade no setor de papel e celulose: uma análise comparativa entre empresas nacionais e transnacionais. 2006. 133 p. Dissertação (Mestrado em Economia) Faculdade de Ciências e Letras, Universidade Estadual Paulista, Araraquara, 2006.

ROMEIRO, A. R.; SALLES FILHO, S. Dinâmica de inovações sob restrição ambiental. In: ROMEIRO, A. R.; REYDON, B., P.; LEONARDI, M. L. A. (Orgs.). Economia do meio ambiente: teoria, políticas e a gestão de espaços regionais. Campinas: Editora da Unicamp/ IE, 1999, p. 83-122.

SÁ, M. T. V. A indústria de bens eletrônicos de consumo frente a uma nova rodada de abertura. 2004.393 p. Tese (Doutorado em Economia) - Instituto de Economia, Universidade Estadual de Campinas, Campinas, 2004.

TOJO, N. Extended producer responsibility as a driver for design change: utopia or reality? 2004. 325 p. Dissertation - The International Institute for Industrial Environmental Economics, Lund University, Sweden, 2004.

UNITED KINGDOM. Department of Trade and Industry [DTI]. Full regulatory impact assessment (RIA) for the Department of Trade and Industry's regulations transposing directive 2002/95/EC of the European Parliament and of the Council on the Restriction of the Use of certain Hazardous Substances in Electrical and Electronic Equipment (the RoHS Directive), as amended, in the United Kingdom. London, 2006. Disponível em: < www.bis.gov.uk/files/ file35230.doc>. Acesso em: 15 maio 2007.

UNITED NATIONS CONFERATION ON TRADE AND DEVELOPMENT [UNCTAD]. Commission on Trade in Goods and Services, and Commodities Intergovernmental Expert Meeting on New and Dynamic Sectors of World Trade. Strengthening participation of developing countries in dynamic and new sectors of world trade: trends, issues and policies in the electronics sector. Geneva, 2005. Disponível em: <http://www.unctad.org/en/docs/ c1em28d2_en.pdf>. Acesso em: 02 ago. 2009.

VELEVA, V.; SETHI, S. The electronics industry in a new regulatory climate: protecting the environment and shareholder value. Corporate Environmental Strategy: International Journal for Sustainable Business, Denver, v. 11, n. 9, p. 207-224, October 2004.

VOSSENAAR, R.; SANTUCCI, L.; RAMUNGUL, N. Environmental requirements and market access for developing countries: the case of electrical and electronic equipment. In: 
UNCTAD (Org.). Trade and Environment Review 2006. Geneva: UNCTAD, 2006, p. 61-91. Disponível em: <http://unctad.org/en/docs/ditcted200512_en.pdf>. Acesso em: 02 ago. 2009.

WILLIAMSON, O. E. Economic organization firms, markets and policy control. New York: New York University Press, 1986.

. The economic institutions of capitalism: firms, markets, relational contracting. New York: The Free Press, 1987.

. Transaction cost economics. In: SCHMALENSEE, R.; WILLIG, R. D. (Eds.). Handbook of industrial organization. Amsterdam: North-Holland, v.1, 1996, p. 136-182.

WORLD TRADE ORGANIZATION [WTO]. World trade report 2005: exploring the links between trade, standards and the WTO. Geneva, 2005. Disponível em: <http://www.wto. org/english/res_e/booksp_e/anrep_e/world_trade_report05_e.pdf>. Acesso em: 08 dez. 2007. MASARU, Y. Public-private partnership in science and tecnology in Japan: a case of materials innovation. In: YAMADA, H. (Ed.). Science and tecnology police in Europe, the United States and Japan. Tokyo: NTT Publishing, 2006, p. 65-101.

ENDEREÇO PARA CORRESPONDÊNCIA:

Stela Luiza de Mattos Ansanelli - stelansa@hotmail.com; stelaluiza@fclar.unesp.br Rodovia Araraquara-Jaú, km 1, Bairro dos Machados, Caixa Postal 174, sala 86 14800-901 - Araraquara (SP)

Tel.: (16) 3357-4115; (16) 3301-6214; (15) 8135-0974 